\title{
Silibinin attenuates adipogenesis in 3T3-L1 preadipocytes through a potential upregulation of the insig pathway
}

\author{
SUN-O KA ${ }^{1}$, KYUNG-AH KIM ${ }^{1}$, KANG-BEOM KWON ${ }^{2}$, JIN-WOO PARK ${ }^{1}$ and BYUNG-HYUN PARK ${ }^{1}$ \\ ${ }^{1}$ Department of Biochemistry, Medical School and Institute for Medical Sciences, \\ Chonbuk National University, Jeonju, Jeonbuk 561-756; ${ }^{2}$ Department of Physiology, \\ School of Oriental Medicine, Wonkwang University, Iksan, Jeonbuk 570-749, Korea
}

Received January 9, 2009; Accepted February 23, 2009

DOI: 10.3892/ijmm_00000174

\begin{abstract}
In the past few decades, the use of silibinin, a plant flavonoid extracted from the milk thistle, as a hepatoprotective and chemopreventive agent has gained much attention. In this study, we investigated the effects of silibinin on adipogenesis. Treatment with silibinin suppressed terminal differentiation of 3T3-L1 cells into adipocytes as evidenced by Oil red $\mathrm{O}$ staining and TG assay results. Real-time RTPCR analysis revealed that silibinin decreased the expression of adipogenesis-related genes such as CAAT/enhancer binding protein- $\alpha$, fatty acid synthase, sterol response element binding protein $1 \mathrm{c}$, adipocyte-specific lipid binding protein, peroxisome proliferator-activated receptor $\gamma$ and lipoprotein lipase, and increased the expression of preadipocyte factor-1, a preadipocyte marker gene. The anti-adipogenic effect of silibinin was associated with the up-regulation of insig-1 and insig-2. Collectively, these results suggest that silibinin inhibits adipocyte differentiation through a potential upregulation of insig-1 and insig-2 at an early phase in adipocyte differentiation.
\end{abstract}

\section{Introduction}

Obesity is a disorder that results from excess white adipose tissue, which can be attributed to both adipocyte hyperplasia and hypertrophy. Hypertrophy is due to excess triacylglyceride (TG) accumulation in the adipocytes, whereas hyperplasia results from the recruitment of new adipocytes from preadipocytes in adipose tissue. The development of hyperplastic adipose tissue is associated with the most severe forms of obesity and has the poorest prognosis for treatment $(1,2)$. The differentiated cells exhibit many of the morphological and biochemical characteristics of adipocytes found

Correspondence to: Dr Byung-Hyun Park, Medical School and Institute for Medical Sciences, Chonbuk National University, Jeonju, Jeonbuk 561-756, Korea

E-mail: bhpark@chonbuk.ac.kr

Key words: silibinin, adipogenesis, insig, 3T3-L1 preadipocytes in white adipose tissue, such as TG accumulation, insulinregulated metabolism and expression of characteristic adipocyte genes, such as CAAT/enhancer binding protein $\alpha$ $(\mathrm{C} / \mathrm{EBP} \alpha)$, peroxisome proliferator-activated receptor $\gamma$ $(\mathrm{PPAR} \gamma)$, fatty acid synthase (FAS), lipoprotein lipase (LPL), sterol response element binding protein (SREBP) and adipocyte-specific lipid binding protein $(\mathrm{aP} 2)(3,4)$. Of these, PPAR $\gamma$ is a master transcription factor for adipogenesis that stimulates the expression of many of the genes necessary for adipogenesis (5).

Feeding normal rats a high fat diet increases the insulininduced gene 1 (insig-1) mRNA levels in white adipose tissue (6). Insig-1 binds to SREBP cleavage activating protein (SCAP), which escorts SREBP from the endoplasmic reticulum to the golgi where the SREBP is proteolytically processed to yield an active transcription factor. The binding of SCAP by insig-1 effectively prevents SREBP activation and thus blocks its action on gene transcription $(7,8)$. It has also been demonstrated that insig-1 restricts lipogenesis in mature adipocytes and blocks differentiation in preadipocytes (9). Insig-2 is a close homolog of insig-1, and also prevents the proteolytic processing of SREBP (7). SREBP1c, an SREBP isoform, activates PPAR $\gamma$ by inducing its expression as well as by promoting the production of an endogenous PPAR $\gamma$ ligand (10).

Silibinin, a plant flavonoid, is the major element extracted from the milk thistle (Silybum marianum). To date, studies conducted on both silibinin and its cruder form, known as silymarin, have focused on the hepatoprotective and chemopreventive effects (11). To our knowledge, the antiobesity effects of silibinin have not yet been reported. In the present study, we investigated the feasibility of using silibinin to prevent adipose conversion.

\section{Materials and methods}

Cell culture. 3T3-L1 cells were cultured in Dulbecco's modified Eagle's medium supplemented with $10 \%$ fetal bovine serum, $100 \mu \mathrm{g} / \mathrm{ml}$ streptomycin and $100 \mathrm{U} / \mathrm{ml}$ of penicillin in a humidified atmosphere of $5 \% \mathrm{CO}_{2} / 95 \%$ air at $37^{\circ} \mathrm{C}$. For the 3T3-L1 differentiation experiments, confluent cells were treated with differentiation medium (MDI: DMEM, $10 \% \mathrm{FBS}, 1 \mu \mathrm{M}$ dexamethasone, $10 \mu \mathrm{g} / \mathrm{ml}$ insulin and $0.5 \mathrm{mM}$ 
Table I. Sequences and accession numbers for primers (forward, FOR and reverse, REV) used in real-time RT-PCR.

\begin{tabular}{|c|c|c|}
\hline Gene & Sequences for primers & Accession No. \\
\hline $\operatorname{PPAR} \gamma$ & $\begin{array}{l}\text { FOR: GAAAGACAACGGACAAATCACC } \\
\text { REV: GGGGGTGATATGTTTGAACTTG }\end{array}$ & NM_011146 \\
\hline aP2 & $\begin{array}{l}\text { FOR: AGCCTTTCTCACCTGGAAGA } \\
\text { REV: TTGTGGCAAAGCCCACTC }\end{array}$ & NM_024406 \\
\hline FAS & $\begin{array}{l}\text { FOR: TGATGTGGAACACAGCAAGG } \\
\text { REV: GGCTGTGGTGACTCTTAGTGATAA }\end{array}$ & NM_007988 \\
\hline LPL & $\begin{array}{l}\text { FOR: GGACGGTAACGGGAATGTATGA } \\
\text { REV: TGACATTGGAGTCAGGTTCTCTCT }\end{array}$ & NM_008509 \\
\hline HSL & $\begin{array}{l}\text { FOR: GGAGCACTACAAACGCAACGA } \\
\text { REV: TCGGCCACCGGTAAAGAG }\end{array}$ & NM_010719 \\
\hline $\mathrm{C} / \mathrm{EBP}-\alpha$ & $\begin{array}{l}\text { FOR: TTGTTTGGCTTTATCTCGGC } \\
\text { REV: CCAAGAAGTCGGTGGACAAG }\end{array}$ & NM_007678 \\
\hline SREBP1c & $\begin{array}{l}\text { FOR: GGTTTTGAACGACATCGAAGA } \\
\text { REV: CGGGAAGTCACTGTCTTGGT }\end{array}$ & NM_011480 \\
\hline Pref-1 & $\begin{array}{l}\text { FOR: GCTGGGACGGGAAATTCTG } \\
\text { REV: TCCAGGTCCACGCAAGTTC }\end{array}$ & NM_010052 \\
\hline Insig-1 & $\begin{array}{l}\text { FOR: TGTGGTTCTCCCAGGTGACT } \\
\text { REV: TAGCCACCATCTTCTCCTCC }\end{array}$ & NM_153526 \\
\hline Insig-2 & $\begin{array}{l}\text { FOR: TGAAGCAGACCAATGTTTCAA } \\
\text { REV: GGTGAACTGGGGGTCTCC }\end{array}$ & NM_133748 \\
\hline GAPDH & $\begin{array}{l}\text { FOR:CGTCCCGTAGACAAAATGGT } \\
\text { REV:TTGATGGCAACAATCTCCAC }\end{array}$ & NM_008084 \\
\hline
\end{tabular}

isobutylmethylxanthine) for 2 days. The medium was then replaced with standard medium containing $5 \mu \mathrm{g} / \mathrm{ml}$ insulin and changed every other day for the following 4 days. Cellular TG content was assayed using a TG assay kit (Sigma, St. Louis, MO) as described previously (12).

Oil red $O$ staining. Cells were washed twice with PBS and fixed with $10 \%$ formaldehyde for $2 \mathrm{~h}$ at room temperature. After washing once with $60 \%$ isopropanol, the cells were stained for $1 \mathrm{~h}$ at room temperature with filtered Oil red $\mathrm{O} / 60 \%$ isopropanol solution. The cells were then washed once with $60 \%$ isopropanol, and once with distilled water. The red-stained adipocytes were observed by light microscopy.

RNA isolation and real-time RT-PCR. Total RNA was extracted from 3T3-L1 adipocytes using a TRIzol reagent (Invitrogen, Carlsbad, CA). RNA was then precipitated with isopropanol and dissolved in diethylpyrocarbonate-treated distilled water. First-strand cDNA was generated with the oligo dT-adaptor primers by reverse transcriptase (Takara, Japan). Specific primers (Table I) were designed using primer express software (Applied Biosynthesis, Foster City, CA). GAPDH was used as the invariant control. The real-time RTPCR reaction, which contained a final volume of $10 \mu 1,10 \mathrm{ng}$ of reverse transcribed total RNA, $200 \mathrm{nM}$ of forward and reverse primers and PCR master mixtures, was performed in 384-well plates using the ABI Prism 7900HT Sequence Detection System (Applied Biosystems). All reactions were conducted in triplicate.

Statistical analysis. All results were expressed as the mean \pm the SEM, and the difference between groups was calculated using the Student's t-test. Differences with a $\mathrm{p}<0.05$ were considered to be statistically significant.

\section{Results}

Effects of silibinin on differentiation of 3T3-L1 cells. We first examined the effects of silibinin on adipocyte differentiation. Upon induction of adipogenesis with MDI, the massive accumulation of cytosolic TG was observed in control cells as visualized by Oil red $\mathrm{O}$ staining. When treated with silibinin during the first 2 days of differentiation, preadipocytes failed to differentiate into adipocytes and still retained their spindle-like features characteristic of preadipocytes. A suppressive effect on adipocyte differentiation was evident with as little as $5 \mu \mathrm{M}$ silibinin and increased in a manner directly related to silibinin concentration (Fig. 1A). Additionally, cellular TG contents were measured to confirm the data from the Oil red $\mathrm{O}$ staining. As shown in Fig. 1B, 
A
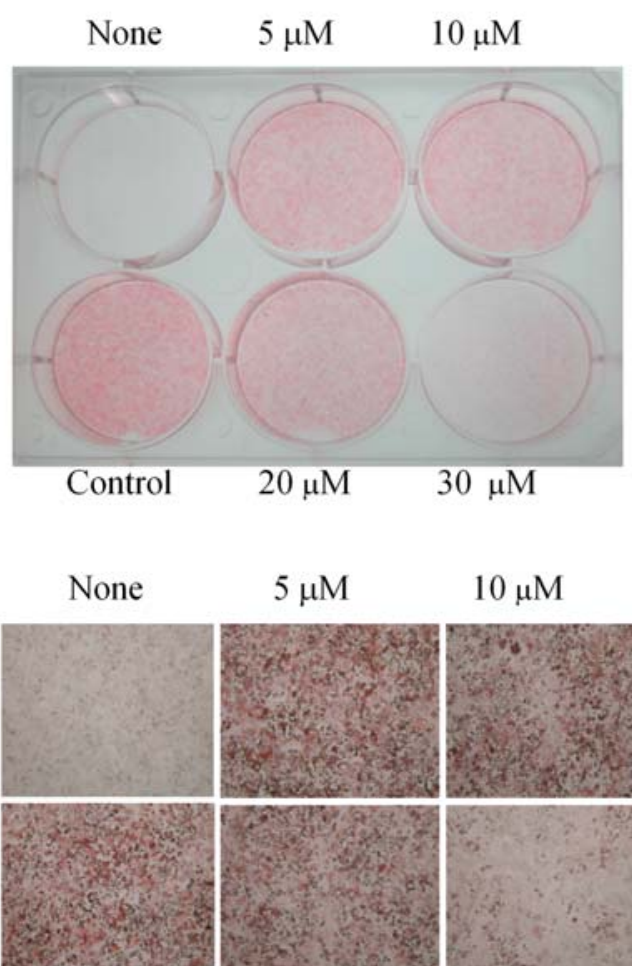

Control
$5 \mu \mathrm{M}$
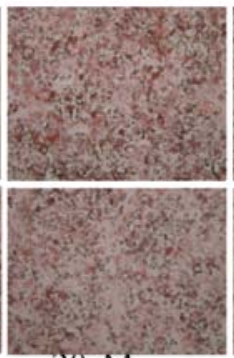

$20 \mu \mathrm{M}$
$10 \mu \mathrm{M}$
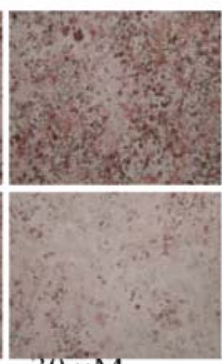

$30 \mu \mathrm{M}$
B

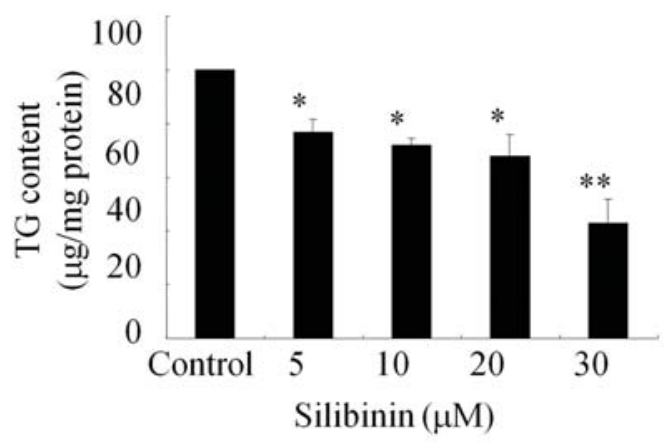

Figure 1. Suppression of adipocyte differentiation by silibinin. (A) 3T3-L1 preadipocytes were grown in the MDI medium in the absence or presence of the indicated concentrations of silibinin for the first 2 days. Six days after the initiation of differentiation, the visualization of lipids by Oil red $\mathrm{O}$ staining and a high magnification (x200) of cells were conducted. (B) Cells were harvested and the TG contents were measured. Values represent mean \pm SEM of three independent experiments. ${ }^{*} \mathrm{p}<0.05 ;{ }^{*} \mathrm{p}<<0.01$ vs. control.
I
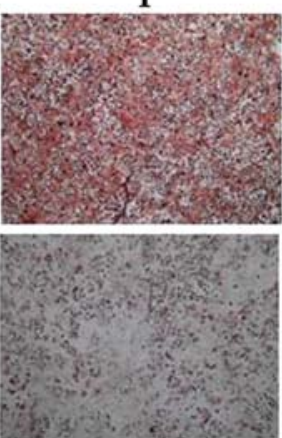

$\mathrm{V}$

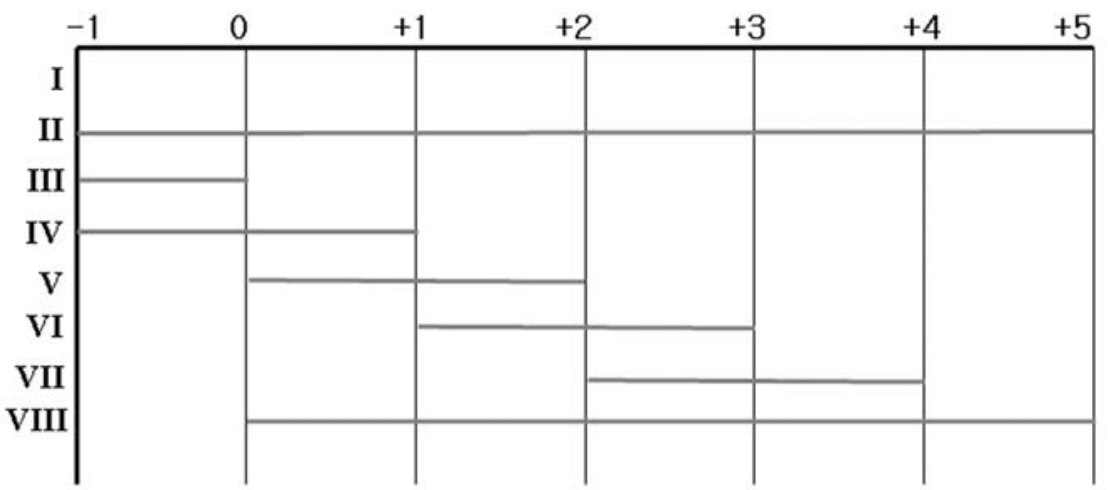

Figure 2. Time-dependent suppression of adipocyte differentiation by silibinin. Differentiating 3T3-L1 preadipocytes were treated with $30 \mu \mathrm{M}$ silibinin for various time periods and stained with Oil red O. Bars indicate the duration of the silibinin treatment. Representative data from three separate experiments are shown.

TG contents were significantly reduced in silibinin-treated 3T3-L1 cells. Silibinin alone did not affect the viability at the concentrations tested (data not shown).
Next, we treated the 3T3-L1 cells with different time-based protocols to determine the critical periods during which silibinin suppresses TG accumulation. As shown in Fig. 2, 

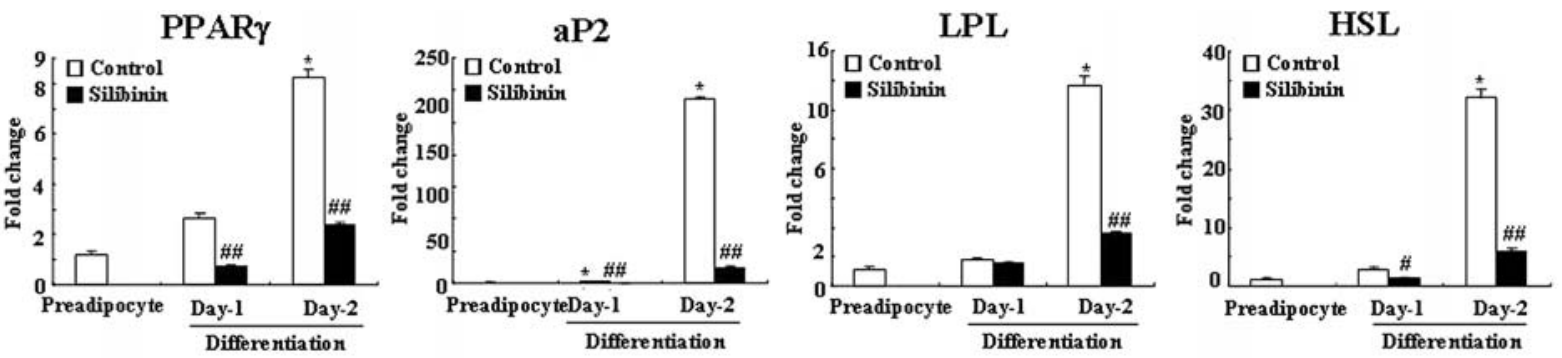

FAS

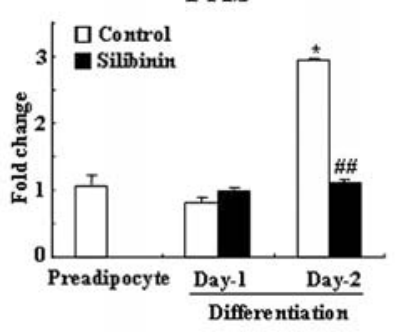

SREBP1C

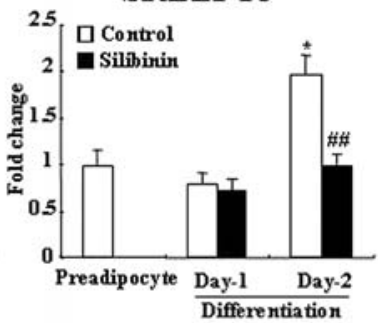

Pref-1

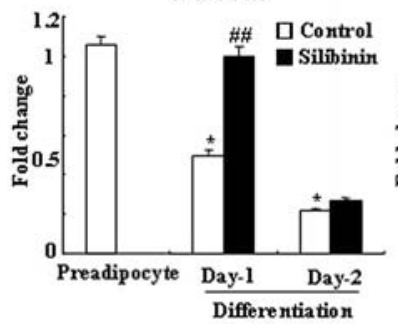

$\mathrm{C} / \mathrm{EBP} \alpha$

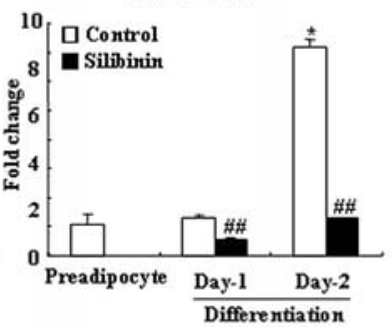

Figure 3. Real-time RT-PCR analysis of adipocyte differentiation marker genes. Differentiating 3T3-L1 preadipocytes were treated with 30 $\mu$ M silibinin for 1 or 2 days. RNA was isolated and adipogenic gene expression was measured by real-time RT-PCR. Each value is expressed as the mean \pm SEM of three independent experiments. ${ }^{*} \mathrm{p}<0.05$, vs. preadipocytes; ${ }^{\#} \mathrm{p}<0.05 ;{ }^{\# \#} \mathrm{p}<0.01$ vs. control.

INSIG-1

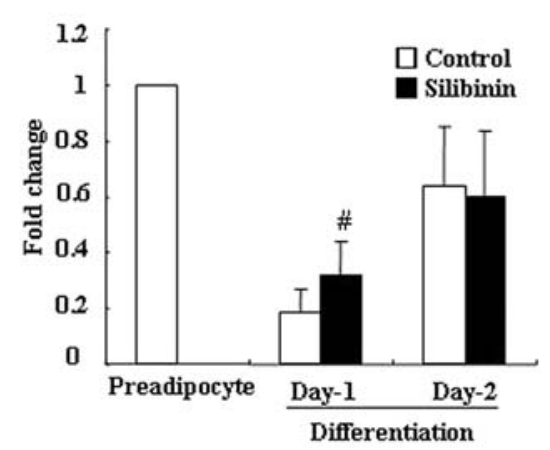

INSIG-2

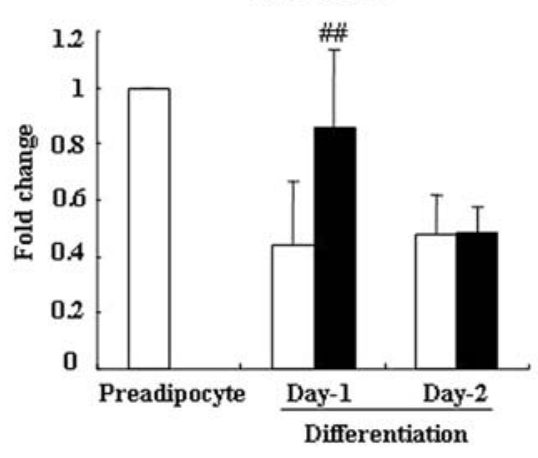

Figure 4. Changes in insig-1 and insig-2 mRNA expression by silibinin. Experimental procedures for the quantification of insig-1 and insig-2 mRNA were the same as described in the legend of Fig. 3. The results of three independent experiments are expressed as the mean \pm the SEM. ${ }^{*} \mathrm{p}<0.05$, vs. preadipocytes; ${ }^{*} \mathrm{p}<0.05$; ${ }^{\# \#} \mathrm{p}<0.01$ vs. control.

treatment with $30 \mu \mathrm{M}$ silibinin for the first 2 days of differentiation induction was sufficient to suppress MDI-induced adipocyte differentiation and TG accumulation. However, treatment of 3T3-L1 cells with silibinin subsequent to the initial 2 days of exposure to MDI showed little effect, suggesting that silibinin itself suppresses adipocyte differentiation, and has no effect on the later lipid accumulation stage.

Effect of silibinin on expression of adipocyte-specific genes. Total RNA was extracted on the 1 st or 2 nd day of differentiation and the expression profiles of adipocyte genes were investigated by quantitative real-time RT-PCR (Fig. 3). In the silibinin-treated cells, the expression levels of $\mathrm{C} /$ EBP- $\alpha$, PPAR $\gamma$, aP2, FAS, LPL and SREBP1c mRNA were several times lower than that of the controls, whereas the expression of pref-1, a preadipocyte marker that normally disappears during adipocyte maturation, increased significantly compared to the control.

Increase of insig-1 and insig-2 expression in silibinin-treated 3T3-L1 cells. Insig-1 and insig-2 are crucial for SREBPdependent gene transcription and the regulation of adipocyte differentiation (7). We therefore investigated the changes of insig-1 and insig-2 mRNA expression levels in silibinintreated 3T3-L1 cells. As shown in Fig. 4, mRNA levels of insig- 1 and insig- 2 increased significantly in the silibinintreated cells.

\section{Discussion}

This study demonstrates that silibinin inhibits the adipose conversion induced by MDI treatment of 3T3-L1 cells. When 3T3-L1 cells are differentiated in the presence of silibinin, 
adipogenesis, as measured by lipid accumulation and induction of several adipocyte-specific marker proteins, is severely inhibited. We have further demonstrated that silibinin inhibited adipogenesis through the induction of insig-1 and insig-2 expression.

The time frame during which silibinin exerts its effect was narrow; 3T3-L1 cells treated with silibinin for the first 2 days suppressed MDI-induced adipocyte differentiation, but cells treated with silibinin at a later stage were not different from control cells. A number of transcription factors have been identified that directly influence adipogenic differentiation. Among these, C/EBPs, PPAR $\gamma$ and SREBP1c have been reported to play a major role (10). Induction of preadipocyte differentiation produces a transient increase in the expression of $\mathrm{C} / \mathrm{EBP} 3$ and $\mathrm{C} / \mathrm{EBP} \delta$, both of which are involved in the activation of $\operatorname{PPAR} \gamma$ and $\mathrm{C} / \operatorname{EBP} \alpha(10,13)$. We therefore characterized the adipocyte gene expression profliles involved in the suppression of adipogenesis by silibinin. Silibinin treatment in an early stage of differentiation caused a significant inhibition of C/EBP- $\alpha$ and PPAR $\gamma$ expression, which would be expected to subsequently reduce late differentiation gene expression and thereby inhibit further differentiation. The results of TG measurement also suggest that silibinin suppresses adipogenesis. Therefore, the anti-adipogenic effect of silibinin in our study is mediated through the down-regulation of the adipogenic program.

The study next examined which signal pathway silibinin uses to regulate the adipogenesis. It is very possible that silibinin works by inducing a regulator that acts as a repressor of adipogenic gene expression. In support of this hypothesis, we proposed that insig proteins were possible targets of silibinin. Previous studies have demonstrated that insig proteins down-regulate the SREBP pathway, and consequently regulate cholesterol and fatty acid metabolism $(7,8)$. In addition, Li et al (9) has demonstrated that insig-1 inhibits adipogenesis in preadipocytes. A recent study done by Krapivner et al (14) suggests the relative importance of insig-2 in adipose metabolism. According to their study, insig- 1 is expressed predominantly in liver tissue, whereas insig- 2 is highly expressed in extrahepatic tissues including adipose tissue. In addition, the change in insig- 2 expression during adipocyte differentiation is greater than that of insig-1 $(9,14)$. In agreement with these studies, we found that the insig-2 mRNA expression was higher than insig-1 mRNA expression in silibinin-treated 3T3-L1 cells. Taken together, silibinin treatment increases the expression of insig proteins, which might reduce the concentration of nuclear SREBP1c and reduce the expression of genes related to the adipogenic program. The molecular mechanism by which silibinin enhances the expression of insig proteins remains obscure. Further studies are needed to elucidate the exact mechanism.

Silibinin treatment decreases adipogenic differentiation in a dose-dependent manner. This effect was observed with as little as $5 \mu \mathrm{M}$ silibinin, and $30 \mu \mathrm{M}$ silibinin almost completely inhibits adipogenic differentiation. Furthermore, the concentrations of silibinin tested in our study were lower than those used in other studies; $100 \mu \mathrm{M}$ was used for primary isolated hepatocytes (15), $300 \mu \mathrm{M}$ concentration for MCF-7 cells (16), and $500 \mu \mathrm{M}$ for primary isolated cardiomyocytes (17). MTT data and morphological observation after silibinin treatment demonstrated that the cells were viable. Thus, our results suggest that the present observations are not due to the non-specific toxic effects of silibinin. Additional in vivo studies are needed to establish if there is a causal association between silibinin treatment and body fat deposition.

\section{Acknowledgements}

This work was supported by the Grant of the Korean Ministry of Education, Science and Technology (The Regional Core Research Program/Center for Healthcare Development Technology).

\section{References}

1. Dizdar O and Alyamac E: Obesity: an endocrine tumor? Med Hypotheses 63: 790-792, 2004.

2. Unger RH: Minireview: weapons of lean body mass destruction: the role of ectopic lipids in the metabolic syndrome. Endocrinology 144: 5159-5165, 2003.

3. Bernlohr DA, Bolanowski MA, Kelly TJ Jr and Lane MD: Evidence for an increase in transcription of specific mRNAs during differentiation of 3T3-L1 preadipocytes. J Biol Chem 260: 5563-5567, 1985.

4. Green $\mathrm{H}$ and Kehinde O: Spontaneous heritable changes leading to increased adipose conversion in 3T3 cells. Cell 7: 105-113, 1976.

5. Tontonoz P, Hu E and Spiegelman BM: Stimulation of adipogenesis in fibroblasts by PPAR gamma 2, a lipid-activated transcription factor. Cell 79: 1147-1156, 1994.

6. Li J, Yu X, Pan W and Unger RH: Gene expression profile of rat adipose tissue at the onset of high-fat-diet obesity. Am J Physiol Endocrinol Metab 282: E1334-E1341, 2002.

7. Goldstein JL, DeBose-Boyd RA and Brown MS: Protein sensors for membrane sterols. Cell 124: 35-46, 2006.

8. Yang T, Espenshade PJ, Wright ME, Yabe D, Gong Y, Aebersold R, Goldstein JL and Brown MS: Crucial step in cholesterol homeostasis: sterols promote binding of SCAP to INSIG-1, a membrane protein that facilitates retention of SREBPs in ER. Cell 110: 489-500, 2002

9. Li J, Takaishi K, Cook W, McCorkle SK and Unger RH: Insig-1 'brakes' lipogenesis in adipocytes and inhibits differentiation of preadipocytes. Proc Natl Acad Sci USA 100: 9476-9481, 2003.

10. Rosen ED, Walkey CJ, Puigserver P and Spiegelman BM: Transcriptional regulation of adipogenesis. Genes Dev 14: 1293-1307, 2000.

11. Raina K and Agarwal R: Combinatorial strategies for cancer eradication by silibinin and cytotoxic agents: efficacy and mechanisms. Acta Pharmacol Sin 28: 1466-1475, 2007.

12. Park BH, Lee Y, Walton M, Duplomb L and Unger RH: Demonstration of reverse fatty acid transport from rat cardiomyocytes. J Lipid Res 45: 1992-1999, 2004.

13. MacDougald OA and Mandrup S: Adipogenesis: forces that tip the scales. Trends Endocrinol Metab 13: 5-11, 2002.

14. Krapivner S, Popov S, Chernogubova E, Hellenius ML, Fisher RM, Hamsten A and van't Hooft FM: Insulin-induced gene 2 involvement in human adipocyte metabolism and body weight regulation. J Clin Endocrinol Metab 93: 1995-2001, 2008.

15. Guigas B, Naboulsi R, Villanueva GR, Taleux N, Lopez-Novoa JM, Leverve XM and El-Mir MY: The flavonoid silibinin decreases glucose-6-phosphate hydrolysis in perfused rat hepatocytes by an inhibitory effect on glucose-6-phosphatase. Cell Physiol Biochem 20: 925-934, 2007.

16. Wang HJ, Tashiro S, Onodera $S$ and Ikejima T: Inhibition of insulin-like growth factor 1 receptor signaling enhanced silibinin-induced activation of death receptor and mitochondrial apoptotic pathways in human breast cancer MCF-7 cells. J Pharmacol Sci 107: 260-269, 2008.

17. Zhou B, Wu LJ, Li LH, Tashiro S, Onodera S, Uchiumi F and Ikejima T: Silibinin protects against isoproterenol-induced rat cardiac myocyte injury through mitochondrial pathway after upregulation of SIRT1. J Pharmacol Sci 102: 387-395, 2006. 